\title{
The Role of Monoclonal Antibody Targeted Therapy in Uterine Sarcomas
}

\author{
CRISTIAN CIRLAN ${ }^{1 *}$, CEZAR IONUT CALIN ${ }^{1}$, RADU COSTEA ${ }^{2}$, ADRIAN GHEORGHE BARBILIAN ${ }^{1,2}$ \\ ${ }^{1}$ Carol Davila Central Universitary Emergency Military Hospital, 134 Calea Plevnei, 010825, Bucharest, Romania \\ ${ }^{2}$ Carol Davila University of Medicine and Pharmacy Bucharest, 37 Dionisie Lupu Str.,020021, Bucharest, Romania
}

\begin{abstract}
The uterine sarcoma is one of the type of neoplasm that affects the abdominopelvine organs. The behaviour of this hystopathological type of cellular line is very aggresive both to the primerorgan and also to the nearby organs and to the main filter' organs like the liver and lung, where it develops metastasis. The treatment of this disease is multidisciplinary and it uses many therapeutic strategies depending on staging and the other comorbidities of the pacient. We will present the case of an 81 year old female known with the diagnosis of relapse tumoral abdominopelvin sarcoma developed one year after total hysterectomy surgery with bilateral anexetomie for the uterine sarcoma. Also we will discuss about a series of characteristics of the treatment plan observed at different similar cases. We will evaluate the latest drug lines used in oncology treatment, we will discuss about the therapeutic indications and in the end we will draw conclusions about the therapeutic indications of each case.
\end{abstract}

Keywords: abdomino-pelvin tumors, sarcoma, multidisciplinary

Sarcomas are rare malignant tumors, being more common in the pediatric population [1]. The sarcoma classification includes more than 100 histological subtypes, [2] but in this paper we will refer to uterine sarcoma, our attention being directed to leiomiosarcoma.

Uterine sarcomas are tumors of the soft tissues derived from mesenchymal cells, and are tumors with a high degree of aggression, with frequent loco-regional and metastasis to distantorgans. The high degree of recurrence, regardless of the stage of the disease at the time of diagnosis, is still a common denominator of sarcomas [3]. The most common types of uterine sarcoma are well and less differentiated endometrial tumors, undifferentiated uterine sarcomas and leiomyosarcomas. Rarely, adenosarcomas and uterine rhabdomyosarcomas can be found in medical practice [4].

Uterine leiomyosarcomas are malignant tumors that develop from myometric cell aberrant mitosis. They typically reach large dimensions (greater than $10 \mathrm{~cm}$ ) [5], with areas of necrosis and haemorrhage being present at a high frequency. The tumor presents estrogen and progesterone receptors, [6] which allows the use of hormonal drugs in the therapeutic scheme of this pathology. The diagnosis of certainty is usually posthistrerectomy or following a myomectomy in case of a leiomyoma suspicion. Clinically, the patient may experience postmenopausal bleeding, abnormal bleeding in premenopause, abdominal pain, bloating, urological manifestations, or in a few cases it may be asymptomatic. Biomorphologic tests are necessary, but imaging (ultrasound, tomography, magnetic resonance) shows extra information about the presence of a tumor and details of localization, homogeneity and consistency, the relationship with the surrounding organs, the extension of neoplasia, the latter being of real use in establishing the therapeutical plan [7[. The relationship with the surrounding organs generally reffers to the cavitous and parenchimatous organs, but may also include the bony pelvis, if local invasion occus; the surgical management of these invasions includes wide excision and reconstruction with grafted bone or metallic augments, often necessitating the use of state-of-the art techniques like $3 \mathrm{D}$ reconstruction and $3 \mathrm{D}$ printing, which were developed for hip and knee reconstructive surgery [8-12].

\section{Experimental part \\ Case presentation}

We present the case of an 81-year-old woman known to be diagnosed with abdominopelvin tumor. The patient is admitted for specific symptomatology related to an intestinal occlusion: slowed intestinal transit for faecal matter, emetised status, inappetence, tegumentary pallor, and increase abdominal volume predominantly in the inferior floor. The patient is dispensarised (taken under surveilance sau hospitalized) through the general practitioner for the following diagnoses: fast-onset atrial fibrillation, essential arterial hypertension, senile dementia, straight breast cancer for which radical mastectomy with axillary lymphadenectomy was practiced abouteightyears ago, total hysterectomy with bilateral annexectomy by classical approach done one year ago - median pubosupraombillical laparotomy that was practiced in another hospital unit for the diagnosis of uterine sarcoma and the result of the anatomopathological bulletin was: the tumor consisting of fusiform cells with intersected fusion cells with high cell density, nucleus with prominent nuclei, mitoses present, thickened blood vessels - aspects strongly suggestive of a sarcoma-like proliferation. After the intervention, the patient performed twelve chemotherapy treatments according to the following regimen: administration of Docetaxel Endoveminous Infusion at three weeks postoperatively and Gemcitabine endovemous infusion starting with day one as well as day eight, a cure consists of Docetaxel + Gemcitabine on day one and Gemcitabine may additionally be given on day eight, and the cycle was repeated on day twenty one. Six standard cycles were performed, hence twelve chemotherapy treatments.

Post-chemotherapy the situation was stable until the resurgence of the locoregional evolution of neoplastic disease. The main modified biomorphic constants worth mentioning which influenced the patient's postoperative evolution were: leucocytes 11,580 / microlitres (normal 
values 3.39-8.86), hemoglobin 10.3g / dl (NV 11.1-14.7), serum sodium 132mmol / L (NV 136-146), glucose 122 $\mathrm{mg} / \mathrm{dL}$ (NV 74-106), $20 \mu \mathrm{g} / \mathrm{dL}$ sideremia (NV 60-180). The patient is subjected to a toraco-abdominal-pelvic nuclear magnetic resonance scan with a contrasting substance indicating the following: uterus is not visualized - surgically ablated; a non-homogeneous tumor formation with a $10 \mathrm{~cm}$ diameter cranio-caudal diameter / 9.2 centimeters antero-posterior / 8 centimeters axial to the pelvis on the right side of the pelvis (fig. 1).

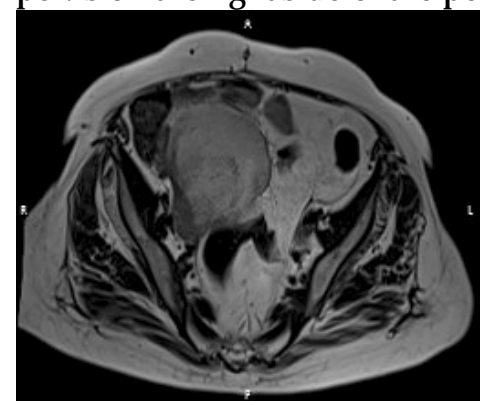

Fig. 1. Abdominal-pelvic image from the patient's contrast MRI

The tumor formation is situated at the back of the rectosigmoid junction which it invades, on the sides comes in contact with the right external iliac vessels, with the ileo-spasus on the right side and on the upper side with the enteral mass invading two ileals in the middle portion of the ileum (fig. 2). The right ureter shows a posterior tract of the tumor, is compressed without being invaded by the tumor.

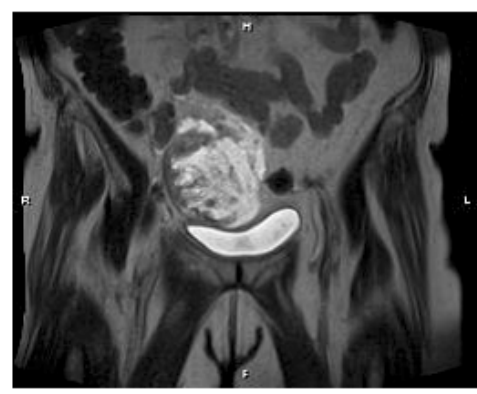

Fig. 2. Abdominal-pelvic image from the patient's contrast MRI

Colonoscopically, the presence of a tumor with extrinsic development is present which also invades the upper rectal mucosa and fixes the rectum wall without being able to be mobilized performing colonoscopic maneuvers. Serial biopsies are collected, establishing the following histological diagnosis: a tumor formation consisting of fusiform cells disposed in intersecting bundles with high cell density, nucleus with prominentnuclei, mitosis present - aspects suggestive of a sarcomatous proliferation. Given the identical microscopic appearance of these biopsies, we consider that this tumor is a sarcoma tumor recurrent after a uterine sarcoma.

During the hospitalization, a hydroelectrolytic and metabolic rebalancing treatment is instituted aiming at the normalization of the biomorphic constants, the cardiological state is re-evaluated and the cardiologic treatment is readjusted by resorting to intravenous drugs. The close monitoring of the cardiac function both in pre-op as well as in post-op care is of significant impact to the outcome of the procedure, and is becoming ever-more complex as new methods of evaluating the outcome of theraputic procedures in cardiac disfunctions are developing [13]. After normalization, or in some cases the improvement of the biohumoral constants, and achievement of a favorable psychological status, surgery is performed. Under general anesthesia with orotracheal intubation, a pubosupombilical medial iterative laparotomy is undertaken. It is difficult to get access to the peritoneal cavity due to multiple adhesions. Intraoperatively, an approximately 14/12/10 centimeter tumorous oval shape is seen, with abdominopelvin location, imprecisely delimited invading the rectosigmoid junction, with several intestinal aneurals in the middle portion of the small intestine, as well as the abdominopelvin peritoneum corresponding to the internal opening of the inguinal canal and the adjacent tissue of this region. The tumor formation, along with the invasive structures, are isolated and the excision of the tumor formation takes place, extensive mandatory enterectomy with laterolateral mechanical ileoil anastomosis, rectosigmoid resection with the distal rectal catarrh, and the proximal endus exodosis in the left iliac anus, the resection of the parietal peritoneum and adjacent connective tissue.

\section{Results and discussions}

Immediately after the intervention the patient is admitted to the Intensive Care Unit where she receives specialized treatment. Two days after surgery the patient's general condition is good, hemodynamic and respiratory stable, reasons for which the patient is transferred to the normal unit. On the forth postoperative day, the evolution is set back by an agitated psychomotor status with a tendency to aggression and distortion of reality, exacerbated symptomatology on the background of senile dementia and voluntary suppression of medication. With the resumption of intestinal transit, the patient is given preponderantlyliquid foods and is then diversified until food intake is normalized. There are difficulties in mobilizing the patient both because of the advanced age and because of the occurrence of a chronic algic syndrome manifested in the internal side of the left thigh. Discharge is performed on day ten after surgery when the patient is in good condition considering the age, stage of disease and other medical conditions. For this therapeutic stage we consider the case as a success, long-term evolution being influenced by multiple factors. Approximately thirty days after the surgery, the histologic diagnosis of the tumoral cell is established (fig. 3), as it is a tumor recurrence of uterine sarcoma for which total hysterectomy with bilateral anexectomy was practiced one year ago.

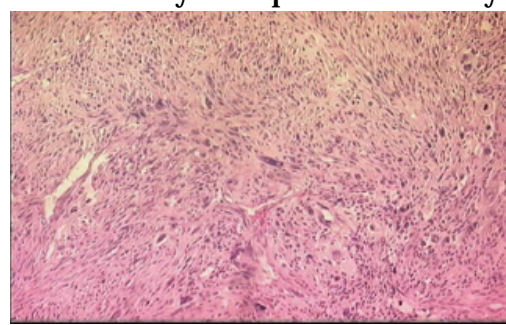

Fig.3. Histologic diagnosis of the tumoral cells

\section{Therapeutic plan in uterine sarcoma}

The treatment plan for uterine sarcomas is adapted depending on the stage of the disease, the current therapeutic strategies being based on treating the patient rather than the disease. Neoplastic pathologies can not benefit from a correct and effective therapeutic attitude in the absence of imaging. Initially, when there is suspicion of a pelvic tumor on the basis of patient's symptoms and bio-humoral investigations, it is recommended to perform a thoraco-abdomino-pelvic computerized tomographic scan with contrast agent to assess the location, size and consistency tumor, relationships with surrounding tissues, or distant extension [14]. Magnetic Resonance and PETCT are imaging investigations that add extra features to describing neoplasia. These methods are also recommended in case of local relapse or residual posthistrectomy abnormalities $[15,16]$. In the case of giant uterine sarcomas that are located unilaterally the patient may present gait abnormalities, with an exaccerbation of pre-existing musculoskeletal conditions such as arthrosis, 
which may be dealt with at a later time in accordance with current protocols, [17-19] or plantar fasciitis and calcaneal spurs, considered a clinical manifestation of preexisting plantar arch collapse and gait disfunction, which in turn has several treatment options [20-22]. A critical moment is the determination of the histopathological type of the tumor and the degree of dysplasia by histopathological examination. Depending on this diagnosis, which is both the diagnosis of certainty and modern imaging, we can place the patient at a stage of evolution of the disease and establish an appropriate treatment plan according to the latest therapeutic guidelines [23]. In this paper we focused on the treatment of uterine leiomyomas to be categorized and staged as follows, in accordance with the TNM/FIGO Classification [4] (tables 1-4).

The degree of differentiation of leiomyosarcomas

G1 - Well-differentiated

G2 - Moderately-differentiated

G3 - Poorly-differentiated

G4 - Dedifferentiated
Surveillance of patients diagnosed with uterine sarcoma in one of the above-mentioned therapeutic lines implies: $[23,24]$.

- Repeat biopsy with histopathological examination every 3-4 months for 2-3 years, then every 6-12 months

- Educating patients about the symptoms of a possible relapse.

Local reoccurances in a patient who did not follow radiotherapy require either immediate administration of these in combination with brachytherapy or systemic therapy, or surgery with resection and radiotherapy together with postoperative systemic therapy [25]. If the patient has received radiotherapy before, resection laparotomy with resection or systemic therapy is required.

Detecting metastasis during surveillance is influenced by the therapeutic approach. The patient will either continue systemic therapy and radiotherapy in case of unresectable metastases, or be directed to a surgical site for ablation of the secondary tumor. In the first case, the patient may have a secondary indication of the response to systemic therapy. When opting for the first phase for metastatic ablation, this should not exclude continued systemic therapy and postoperative.

Table 1

T- PRIMARY TUMOR

\begin{tabular}{|l|l|l|}
\hline TNM & FIGO & Surgical-Pathologic Findings \\
\hline Categories & Stages & \\
\hline TX & & Primary tumor cannot be assessed \\
\hline T0 & & No evidence of primary tumor \\
\hline Tis & & Carcinoma in situ (preinvasive carcinoma) \\
\hline T1 & I & Cervical carcinoma confined to the cervix (disregard extension to the corpus) \\
\hline T1a & IA & $\begin{array}{l}\text { Invasive carcinoma diagnosed only by microscopy; stromal invasion with a maximum depth of } \\
5.0 \text { mm measured from the base of the epithelium and a horizontal spread of } 7.0 \text { mm or less; } \\
\text { vascular space involvement, venous or lymphatic, does not affect classification }\end{array}$ \\
\hline T1a1 & IA1 & Measured stromal invasion $\leq 3.0 \mathrm{~mm}$ in depth and $\leq 7.0$ mm in horizontal spread \\
\hline T1a2 & IA2 & Measured stromal invasion $>3.0$ mm and $\leq 5.0$ mm with a horizontal spread $\leq 7.0$ mm \\
\hline T1b & IB & Clinically visible lesion confined to the cervix or microscopic lesion greater than T1a/LA2 \\
\hline T1b1 & IB1 & Clinically visible lesion $\leq 4.0 \mathrm{~cm}$ in greatest dimension \\
\hline T1b2 & IB2 & Clinically visible lesion $>4.0 \mathrm{~cm}$ in greatest dimension \\
\hline T2 & II & Cervical carcinoma invades beyond uterus but not to pelvic wall or to lower third of vagina \\
\hline T2a & IIA & Tumor without parametrial invasion \\
\hline T2a1 & IA1 & Clinically visible lesion $\leq 4.0 \mathrm{~cm}$ in greatest dimension \\
\hline T2a2 & IIA2 & Clinically visible lesion $>4.0 \mathrm{~cm}$ in greatest dimension \\
\hline T2b & IIB & Tumor with parametrial invasion \\
\hline T3 & III & $\begin{array}{l}\text { Tumor extends to pelvic wall and/or involves lower third of vagina and/or causes hydronephrosis } \\
\text { or nonfunctional kidney }\end{array}$ \\
\hline T3a & IIIA & Tumor involves lower third of vagina, no extension to pelvic wall \\
\hline T3b & IIIB & Tumor extends to pelvic wall and/or causes hydronephrosis or nonfunctional kidney \\
\hline T4 & IV & $\begin{array}{l}\text { Tumor invades mucosa of bladder or rectum and/or extends beyond true pelvis (bullous edema is } \\
\text { not sufficient to classify a tumor as T4) }\end{array}$ \\
\hline T4a & IVA & $\begin{array}{l}\text { Tumor invades mucosa of bladder or rectum (bullous edema is not sufficient to classify a tumor } \\
\text { as T4) }\end{array}$ \\
\hline T4b & IVB & Tumor extends beyond true pelvis \\
\hline
\end{tabular}

Table 4

STAGE GROUPING

Table 2

$\mathrm{N}$ - REGIONAL LYMPH NODES

\begin{tabular}{|l|l|}
\hline NX & Regional lymph nodes cannot be assessed \\
\hline N0 & No regional lymph node metastasis \\
\hline N1 & Regional lymph node metastasis \\
\hline
\end{tabular}

Table 3

M-DISTANT METASTASIS

\begin{tabular}{|l|l|}
\hline M0 & No distant metastasis \\
\hline M1 & $\begin{array}{l}\text { Distant metastasis (including peritoneal spread; involvement of supraclavicular, } \\
\text { mediastinal, or para-aortic lymph nodes; and lung, liver, or bone) }\end{array}$ \\
\hline
\end{tabular}

REV.CHIM.(Bucharest)

No. 11

• 2018

http://www.revistadechimie.ro

\begin{tabular}{|l|l|l|l|}
\hline Stage 0 & Tis & N0 & M0 \\
\hline Stage IA & T1a & N0 & M0 \\
\hline Stage IA1 & T1a1 & N0 & M0 \\
\hline Stage IA2 & T1a2 & N0 & M0 \\
\hline Stage IB & T1b & N0 & M0 \\
\hline Stage IB1 & T1b1 & N0 & M0 \\
\hline Stage IB2 & T1b2 & N0 & M0 \\
\hline Stage IIA & T2a & N0 & M0 \\
\hline Stage IIB & T2b & N0 & M0 \\
\hline Stage IIIA & T3a & N0 & M0 \\
\hline Stage IIIB & T1, T2, T3a & N1 & M0 \\
\hline & T3b & Any N & M0 \\
\hline Stage IVA & T4 & Any N & M0 \\
\hline Stage IVB & Any T & Any N & M1 \\
\hline
\end{tabular}


The results obtained recommend the realization of interdisciplinary research for the use of robotic biointerfaces [26-28].

The current chemotherapy treatment:

At this moment, the recommend and trustworthy therapeutic regiments are:

- sistemic therapy with doxorubicin a with or without oloratumab or gemcitabine

- inhibitors of aromataza for the well defined tumours

\section{Antracicline}

In this group is doxorubicin. Studies had shown that combined with oloratumab it gives better chances of survival in faze ll of randomisation. Antraciclin binds directly to DNA, inhibiting synthesis and fragmentation of DNA. It metabolises in the liver and it excrets through bile in to the digestive tract but also through urine as an active metabolite. Doxorubin is administered as an intravenous infusion, with constant medical observation both during and after administration.

Cleareance:

- infants and children younger than 2 years $=813 \mathrm{~mL} /$ min/square meter

- children older than 2 years and teenagers $=1540 \mathrm{~mL} /$ min/square meter

- adults = 324 to $809 \mathrm{~mL} / \mathrm{min} / \mathrm{square}$ meter (higher for males)

The systemic clearance is semnificant smaller for the obese patients.

Side effects: cardiotoxicity (atrio-ventricular block, bradycardia, arterial or ventricular extrasistols, depolarisation changes, heart failure), hair loss, pruritus, amenorrhea, abdominal pain, hyperuricemia, anorexia, gastrointestinal ulcer, leukopenia, neuropenia, anemia, trombocytopenia and changes in the colour of the tear, saliva and sweat secretions.

\section{Pazopanib}

Pazopanib is a selective inhibitor of tirozin kinaza that blocks the tumoral development and angiogenesis. It acts on the receptor for vascular grown factor, platelet and fibroblast. Among the side effects we mention: nausea, vomiting, diarrhea, loss of appetite, hyperglycaemia, high blood pressure, hypocalcemia, hypomagnesemia, hypokalemia, proteinnuria, hair lose, abdominal pain, increase of transaminases, myelosuppression. The risk of liver failure is low, but there were reported sever cases of liver failure.

The mechanism of action: the tirozin kinaza inhibitors limits tumor development by inhibiting the VRGF-2, VEGFR2, VEGFR-3(vascular endothelial grown factor), pdgfr-alpha and beta( platelet-derived growth factor), FGFR-1, FGFR-3 factors, the cytokine receptors, IL- receptors.

Pharmacodynamics:

- proteine binding more than $99 \%$

- liver metabolism

- the bioavailability increases with food ingestion and decreases when fragmented doses

- in case of liver damage is recommended to lower the

\section{Olaratumab}

Olaratumab is a recombined human monoclonal antibody used with antracicline in the treatment of the advanced stages of soft tissue sarcoma. The action mechanism of olaratumab consists in binding and blocking the alpha receptor of the growth factor derived from platelets(PDGFR-alpha). the receptor is located in many neoplastic tissues, like sarcoma. At this level is involved in cell growth and differentiation, its activation causing cellular proliferation and distant metastasis. The treatment with olaratumab implies that the tumor has no indication for surgery nor radiotherapy.

The gastrointestinal toxicity consists in ; nausea, vomiting,diarrhea and abdominal pain when administered in combination with doxorubicin in compared to the mono therapy with doxorubicin.

The liver toxicity consistsn in lymphopenia stage 3-4, neutropenia and thrombocytopenia, more severe in dual therapy.

Side effects: fatigue, hair loss, hipoglycemia, nausea, lymphocytopenia, musculoskeletal pain and increase of alkaline phosphatase.

\section{Conclusions}

As shown in the presentation we can tell that the uterine sarcoma is an aggressive form of oncological disease, with an unfavourable evolution both through the speed of extension and also through the fact that it affects women all ages and no matter of the hormonal status. The complexity of treating this disease is caused by the many factors involved in the establishment of a medical conduct. A very important fact is represented by the stage of the disease, in other words the time passed from the beginning of the illness to the moment of diagnostic. Most of the time the symptoms that lead the pacient to a medical consult are the symptoms given by the extension of the disease, even the presence of metastases and their extension and because of this the treatment is mostly palliative. Another fact that is very important in the success of the treatment is the interdisciplinary cooperation of the medical team. Considering the many therapeutic resources and the fast acces to the latest medical discoveries we consider that the best approach is an aggressive one but only in the best interest of the patient, in other words we recommend a full hysterectomy with bilateral anexectomy and radical limfadenectomy, full resection of the tumor, the resection of the metastases and oncologycal therapy and radiotherapy. In order to have the best results we must not forget that prevention is the key to success. And if we talk about prevention, in case of minimal invasive treatment of uterine tumours believed to be benign, we have a risk to influence in a bad way the evolution of the sarcoma with uterine starting point when we perform a robotic or laparoscopy procedure that needs to use the morcellator.

About $5 \%$ of these tumors considered first to be benign turned out to be different types of cancer and in the case of intraabdominal morcellation the consequences can be serious from two points of view: the destruction of the specimen which leads to the impossibility of a correct staging and the distance inseminatin that involves a very bad prognosis because of the fast metastases and the tumor recurrence.

In the end, we recommend to plan interest groups for the genital pathology of sarcoma origin, that includes different specialities like oncology, radiotherapy, gynaecology, general surgery, thoracic surgery, orthopedics, gastroenterology, pathological anatomy and imagistics.

\section{References}

1. SIEGEL R.L., MILLER K.D., JEMAL A., Cancer statistics, 2018, CA Cancer J Clin., 68(1), 2018, p. 7.

2. FLETCHER C.D.M., BRIDGE J.A., HOGENDOORN P.C.W., MERTENS F., World Health Organization Classification of tumours of soft tissue and bone, 4th ed, IARC Press, Lyon 2013. 
3. TROPE C.G., ABELER V.M., KRISTENSEN G.B., Diagnosis and treatment of sarcoma of the uterus. A review, Acta Oncol, 51(6), 2012, p. 694-705.

4. KURMAN R.J ., CARCANGIU M.L., HERRINGTON C.S., YOUNG R.H., WHO Classification of tumours of the female reproductive oragans, Vol. 6, 2014.

5. BELL S.W., KEMPSON R.L., HENDRICKSON M.R., Problematic uterin smooth muscle neoplasms. A clinicopathologic study of 213 cases, Am. J. Surg. Pathol., 18(6), 1994, p. 535.

6. QUADE B.J., Pathology, cytogenetisc and molecular biology of uterin leiomyomas and other smooth muscle lessions, Curr Opin Obstet Gynecol, 7(1), 1995, p. 35.

7. HALDORSEN I.S., SALVESEN H.B., What is the best preoperative imaging for endometrial cancer?, CurrOncol Rep, 18(4), 2016, p. 25. 8. PLAVITU A., POGARASTEANU M.E., MOGA M., BARBILIAN C.R., STOICA I.C., ROBU G.C., OPROIU A.M., JINGA M., IFRIM C.F., MRI versus $C T$ as image data source for $3 D$ printing bone,. s.l.: Rev. Chi. (Bucharest), 69, no. 10, 2018, p. 2881-4.

9. RAU, K. RADERMACHERF., PORTHEINEA., ZIMOLONGCH., EICHHORNH. -W., STAUDTEG., Image guided Orthopedic Surgery using individual templates: Experimental results and aspects of the development of a demonstrator for pelvis surgery,. s.l. : CVRMedMRCAS Lecture Notes in Computer Science, 1205, 1997, p. 606-15.

10. BOSE S., VAHABZADEH S., BANDYOPADHYAY A., Bone tissue engineering using $3 D$ printing, Materials Today, 16(12), 2013, p. 496504.

11. PLAVITU A., POGÃRÃ'TEANU M. E., MOGA M., LUPUSORU M., IONITA RADU F., EDU A., 3D Printing as a Way of Integrating Mathematical Models in Arthroscopic Knee Surgery, Rev. Chim. (Bucharest), 69, no. 9, 2018, p. 2501-7.

12. SEITZ H., RIEDER W., IRSEN S., LEUKERS B., TILLE C., Three dimensional printing of porous ceramic scaffolds for bone tissue engineering, Journal of Biomedical Materials Research. Part B: Applied Biomaterials, 74B(2), 2005, p. 782-8.

13. COCULESCU B.I., DINCA G.V., MANOLE G., PURCAREA V.L., OPROIU A.M., STOCHECI C.M., Serum Concentration of hsCRP - Possible Marker for Therapy Evaluation in Left Ventricular Dysfunction with Preserved Ejection Fraction, Rev. Chim. (Bucharest), 69, no. 10, 2018, p. 2885-990.

14. LAKHAM Y., KATZ S.S., GOLDMAN D.A., ET AL., Diagnostic performance of computed tomography for preoperative staging of patients with non-endometrioid carcinomas of the uterin corpus, Ann SurgOncol, 23(4), 2016, p. 1271-8.

15. SALA E., ROCKALL A.G., FREEMAN S.J ., ET AL., The added role of $M R$ imaging in treatment stratification of patients with gynecologic malignancies: what the radiologist needs to know, Radiology, 266(3), 2013, p. 717-40.

16. VARGAS H.A., AKIN O., ZHENG J ., ET AL., The value of MR imaging when the site of uterin cancer origin is uncertain, Radiology, 258(3), 2011, p. 785-92.
17. MAYR H.O., RUESCHENSCHMIDT M., SEIL R., DEJ OUR D., BERNSTEIN A., SUEDKAMP N., STOEHR A., Indications for and results of arthroscopy in the arthritic knee: a European survey, International Orthopaedics (SICOT) , 37, 2013, p. 1263-1271.

18. MOGA M., POGARASTEANU M. E., EDU A., Arthroscopy in Arthrosis: Is It Worth it? - A case Presentation, Rev. Chim. (Bucharest), 69, no. 8, 2018, p. 2232-5.

19. MOSELEY J .B., O'MALLEY K., PETERSEN N., MENKE T., BRODY B., KUYKENDALL D., HOLLINGSWORTH J., ASHTON C., WRAY N., A controlled trial of arthroscopic surgery for osteoarthritis of the knee, The New England J ournal of Medicine, 347(2), 2002, p. 81-88.

20. WANG W, RIKHRAJ IS , CHOU ACC, CHONG HC, KOO KOT ., Endoscopic Plantar Fasciotomy vs Open Radiofrequency Microtenotomy for Recalcitrant Plantar Fasciitis, FootAnkle Int., 39(1), 2018, p. 11-17.

21. MARAFKO C., Endoscopic partial plantar fasciotomy as a treatment alternative in plantar fasciitis, Acta Chir Orthop Traumatol Cech., 74(6), 2007, p. 406-9.

22. MOGA M., POGARASTEANU M. E., EDU A., Arthroscopic Equipment Used in the Treatment of Calcaneal Spurs - A case presentation, Rev. Chim. (Bucharest), 69, no. 8, 2018, p. 2228-31.

23.*** National Comprehensive Cancer Network Guidelines Uterine Sarcoma version 1.2019.

24. SALANI R, KHANNA N, FRIMER M, ET AL., An update on posttreatment surveillance and diagnosis of recurrence in woman with gynecologic malignancies, Society of Gynecologic Oncology (SGO) recommendations, Gynecol Oncol, 146, 2017, p. 3-10.

25. SAVULESCU F., IORDACHE I., ALBIA O., HRISTEA R., DUMITRU C., IORDACHE A., BALASA G., IORDACHE C., LEAU D., ROGIN T., VIRJ OGHE V., Giant uterine leiomyoma, Chirurgia, 106, 2011, p. 665-8 26. ANA MARIA OPROIU, IOAN LASCAR, OCTAVIAN DONTU, CATALIN FLOREA, RODICA SCARLET, IOANA SEBE, LIDIA DOBRESCU, CARMEN MOLDOVAN, CATALIN NICULAE, ROMICA CERGAN, DANIEL BESNEA, SUZANA CISMAS, DRAGOMIR DAVID, DRAGOS MURARU, TIBERIU NEAGU, MARK EDWARD POGARASTEANU, CRISTIAN STOICA, ANTOINE EDU, CHEN FENG IFRIM, Topography of the Human Ulnar Nerve for Mounting a Neuro-Prosthesis with Sensory Feedback, Rev. Chim. (Bucharest), 69, no. 9, 2018, p. 2494

27.CARMEN MOLDOVAN, LIDIA DOBRESCU, VIOLETA RISTOIU, BOGDAN FIRTAT, SILVIU DINULESCU, COSTIN BRASOVEANU, MARIAN ION, DRAGOS DOBRESCU, ROXANA GHEORGHE, ANA MARIA PASCALAU, MARK POGARASTEANU, BOGDAN IOAN COCULESCU, ANA MARIA OPROIU, Experimental Measurements in the Acquisition of Biosignals from a Neuronal Cell Culture for an Exoprosthesis Command, Rev. Chim. (Bucharest), 69, no. 10, 2018, p. 2948

28.A. M. OPROIU, I. LASCAR, C. MOLDOVAN, O. DONTU, M. PANTAZICA, C. MIHAILA, C. FLOREA, L. DOBRESCU, I. SEBE, R. SCARLET, D. DOBRESCU, T.NEAGU, O. IONESCU, I. C. STOICA AND A. EDU, Peripheral Nerve WIFI Interfaces and Electrodes for Mechatronic Prosthetic Hand, ROMJ IST Volume 21, Number 2, 2018, PP. 129-138

Manuscript received: 20.08 .2018 